\title{
The Impact of Emotional Intelligence on Work Stress (Applied Study: Al-Ajami Educational Administration)
}

\author{
Omneya Eid Amin Hussain, Mohamed Abdel Salam Ragheb, Abdel-Nasser Ghanem, \\ Ayman Ahmed Ragab
}

The Arab Academy for Science and Technology \& Maritime Transport, Alexandria, Egypt

Email: omneyaaidhussain@gmail.com

How to cite this paper: Hussain, O.E.A., Ragheb, M.A.S., Ghanem, A.-N. and Ragab, A.A. (2021) The Impact of Emotional Intelligence on Work Stress (Applied Study: Al-Ajami Educational Administration). Open Access Library Journal, 8: e8023.

https://doi.org/10.4236/oalib.1108023

Received: September 29, 2021

Accepted: October 26, 2021

Published: October 29, 2021

Copyright $\odot 2021$ by author(s) and Open Access Library Inc.

This work is licensed under the Creative Commons Attribution International License (CC BY 4.0).

http://creativecommons.org/licenses/by/4.0/

\begin{abstract}
This study aims to examine the impact of emotional intelligence on the work stress of the Al-Ajami Educational Administration. This study used a questionnaire prepared for this purpose. For achieving study goals, the analytical descriptive methodology is used through many; statistical approaches especially multiple regression analysis for testing the effect of more than an independent variable on one dependent variable and hierarchical regression analysis for measuring the adjusted effect of work stress. A randomized stratified sample of the study population was selected by (401) individuals with a response rate of $(80.2 \%)$. The results of the study showed a significant effect of emotional intelligence on work stress. According to the findings, some recommendations are: Organizations should pay more attention to emotional intelligence and its role in reducing work stress.
\end{abstract}

\section{Subject Areas}

Human Resource Management

\section{Keywords}

Emotional Intelligence, Work Stress

\section{Introduction}

The typical organization today operates in a turbulent environment. The rate of technological change is phenomenal, giving rise to hopes and anxiety [1].

There has been an increasing interest in how emotional intelligence affects everyday life transactions. It has been claimed that emotional intelligence is an 
important factor in determining both work climate success and psychological well-being [2].

Work stress has become an important and significant factor in today's competitive and rapidly changing environment, which results in substantial costs to employees and organizations [3].

Emotional intelligence has been found to be an important predictor of various enviable organizational outcomes, such as job performance, job satisfaction, organizational citizenship behavior, and organizational commitment [4].

Emotional intelligence can be defined as "the capability to be conscious to express oneself, to be cognizant of, distinguish, and identify with others, to manage solid emotions and immediate one's motivations, to have the ability to alter in any change and to take care of issues of an individual or a social nature" [1].

Emotional intelligence involves managing feelings so that they are expressed appropriately, therefore enabling people to work together towards common goals in a constructive and transparent environment. When the executive values feelings, so will the employees [5]. Thus, if the manager feels optimistic, confident, creative, flexible, tolerant, respectful, and compassionate, the employees will likely mirror these feelings [6].

Job stress has become a common term in today's parlance. In every organization, the main cause of low productivity appears to be stress at the workplace [7].

There is confirmation that emotional intelligence influences the job satisfaction of representatives. Mindfulness of interpersonal feelings can help the regulation of contrary emotions and feelings and hence the individual will have improved performance in their occupation; better performance will thus set the establishments for job satisfaction [8].

Stress is characterized by its physical and physiological impacts on an individual and might be a mental, physical or emotional strain. Occupational stress can happen when there is an inconsistency between the requests of the environment/workplace and a person's capability to complete and complete these requests [9].

Nowadays, work stress has become more apparent and leads to the low morale of employees. The causes for work stress can be attributed to technological changes, competitive lifestyles and various other social factors [10]. Work stress is a double-edged sword; it can be both productive and counter-productive. It can be productive when it helps or motivates people to work more and perform well. It will allow them to explore opportunities and leads to enhanced work productivity [11].

Employees need certain kinds of motivation and work stress mitigating strategies to overcome the stress. Many researchers argued that emotional intelligence may reduce work stress among employees of all management levels. Accordingly, the main problem of the research can be formulated in the form of the following question:

- What is the impact of emotional intelligence on the work stress of Al-Ajami 
Educational Administration?

Besides, the main objective of this research is to test the impact of emotional intelligence on work stress, which will help reduce job stress. This aim will be achieved through some objectives, which are exploring the dimensions of emotional intelligence and work stress.

In the following paper, we will discuss objectives, questions, hypothesis and methodology of the research aiming to have results lead to reach a set of recommendations.

\section{Research Design}

\subsection{Objectives of the Research}

The objectives of the research are:

- Investigation the impact of emotional intelligence on work stress of employees of Al-Ajami Educational Administration.

- Reviewing the concepts of emotional intelligence and work stress.

- Reaching out to a set of recommendations that, if implemented, are expected to lead to reducing work stress and achieving employees" satisfaction.

\subsection{Research Questions}

- Is there a statistical relationship with a significant impact between emotional intelligence and work stress?

- Is there a statistically significant effect of emotional intelligence on conflict ambiguity?

- Is there a statistically significant effect of emotional intelligence on role conflict?

- Is there a statistically significant effect of emotional intelligence on performance evaluation?

- Is there a statistically significant effect of emotional intelligence on physical work factors?

- Is there a statistical difference of emotional intelligence on conflict ambiguity due to: gender, experience, educational level and managerial levels?

\subsection{Research Model}

Figure 1 shows the research model of this study.

\subsection{Research Hypothesis}

In order to try to answer the research questions, according to the literature review and previous studies, the following hypothesis was developed to decide if there is a significant impact of emotional intelligence on work stress:

- There is a statistically significant effect of emotional intelligence on conflict ambiguity.

- There is a statistically significant effect of emotional intelligence on role conflict. 


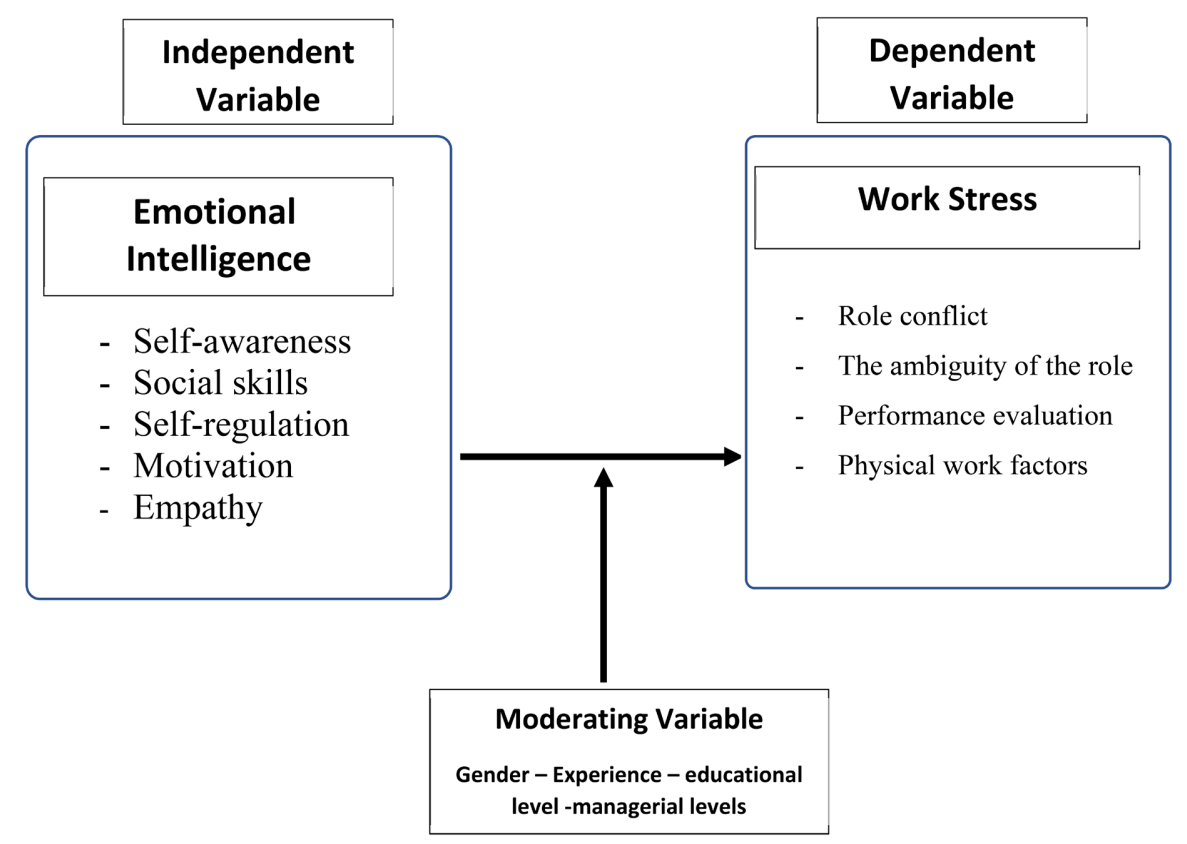

Figure 1. Research model of this study.

- There is a statistically significant effect of emotional intelligence on performance evaluation.

- There is a statistically significant effect of emotional intelligence on physical work factors.

- There is a statistical difference in emotional intelligence on conflict ambiguity due to: gender, experience, educational level and managerial levels.

To verify first four hypotheses, researcher used multiple regression analysis and for the fifth hypothesis, used hierarchical regression analysis for measuring the adjusted effect of work stress.

\section{Research Methodology}

The study adopted a descriptive-analytical method, the questionnaire was the study's main tool for collecting data; where (500) questionnaires were distributed, and (401) questionnaires were retrieved for analysis, the rate was (80.2\%) of the distributed questionnaires. Analyzing data was conducted using a set of statistical methods including means, standard deviation, exploratory factor analysis, multiple linear regression and hierarchical regression analysis using SPSS-V23 and AMOS-V23.

One of the most significant strengths of this study refers to its focus on the Egyptian model where there is a distinct lack of research on the topic there.

\subsection{Study Tool}

In order to collect data, a researcher-made questionnaire based on literature review and previous studies, questionnaires have three sections: emotional intelligence, work stress and basic respondent demographic data. 
The 40-item scale of emotional intelligence section is based on (Madi, 2014), [12] and (Elshawa, 2015) [13]. There were (9) items measuring Self-awareness, (10) items measuring Social skills, (7) items measuring Self-regulation, (8) items measuring Motivation, and (6) items measuring Empathy.

The 30-item scale of emotional intelligence section is based on (Banat, 2009) [14]. There were (7) items measuring role conflict, (6) items measuring the ambiguity of the role, (9) items measuring performance evaluation, and (8) items physical work factors.

Table 1 shows the sources of the questionnaire items and the number of items that were developed from previous studies.

Responses to all items scales were anchored on a five (5) point Likert scale for each statement which ranges from (5) "full agreement", (4) for "agree", (3) for "neutral", (2) for "disagree", and (1) for "full disagreement".

\subsection{Pilot Study}

In order to testing questionnaire validity and reliability, the researcher distributed a survey sample of (32) questionnaires.

The reliability of the study questionnaire was verified by Cronbach's Alpha coefficient, and the results showed the Cronbach Alpha coefficient (86.4) which is a statistically acceptable level as long as it is greater than (0.7) [15].

\section{Hypothesis Testing Results}

\subsection{First Main Hypothesis Test}

\subsubsection{The First Main Hypothesis}

At the level of significance (0.05) there is a statistically significant effect of emotional intelligence (self-awareness-social skills-self-regulation-motivationempathy) on work pressures.

Table 1. Questionnaire's source.

\begin{tabular}{cc}
\hline Variable & Source \\
\hline Independent Variable: Emotional intelligence & \\
Self-awareness & \\
Social skills & (Madi, 2014) [12]; (Elshawa, 2015) [13] \\
Self-regulation & \\
Motivation & \\
Empathy & \\
role conflict & \\
Dependent Variable: Work stress & \\
the ambiguity of the role & \\
performance evaluation & \\
physical work factors &
\end{tabular}


To test this hypothesis, multiple regression analysis was used to verify the effect of emotional intelligence (self-awareness-social skills-self-regulationmotivation-empathy) on work stress. As shown in Table 2.

From Table 2 it is clear that at the level of significance (0.05) there is a significant effect of statistically significant effect of emotional intelligence on work stress, as the value of the level of statistical significance (Sig) in the analysis of variance ANOVA corresponding to the value $(\mathrm{F})$ Calculated is less than 0.05, and the coefficient of determination $\left(\mathrm{R}^{2}\right)$ is 0.53 , which means that emotional intelligence has explained $53 \%$ of the impact or change in work stress, while there are $47 \%$ due to other factors that the model did not address, as it is clear that all dimensions of intelligence Emotional (self-awareness-social skillsself-regulation-motivation) with the exception of (empathy) has a significant effect or statistical significance on work stress, as the level of statistical significance (Sig) for the regression coefficients is less than 0.05 , as the value of the level of statistical significance (Sig) For the regression coefficients, in order, the dimensions of emotional intelligence (self-awareness-social skills-self-regulation-motivation-empathy) are $(0.000,0.023,0.014,0.000,0.10)$ and they are all less than 0.05 except for the value of the level of significance for the dimension (empathy) greater than 0.05 .

It is also clear that the most influential dimensions of emotional intelligence on work stress are (self-awareness), as it has the highest value of (Beta) coefficient of 0.39 , followed by (motivation) 0.20 , then (self-regulation) 0.13 , then (social skills) 0.10 , and finally (empathy) 0.07 .

\subsubsection{Sub-Hypothesis}

To investigate the effect of emotional intelligence (self-awareness-social skillsself-regulation-motivation-empathy) on each dimension of work stress, the main hypothesis was divided into four sub-hypotheses, as follows:

\section{The first sub-hypothesis}

At the level of significance (0.05) there is a statistically significant effect of emotional intelligence (self-awareness-social skills-self-regulation-motivation-empathy) on the role conflict.

To test this hypothesis, multiple regression analysis was used to verify the

Table 2. Multiple regression the effect of emotional intelligence on work stress.

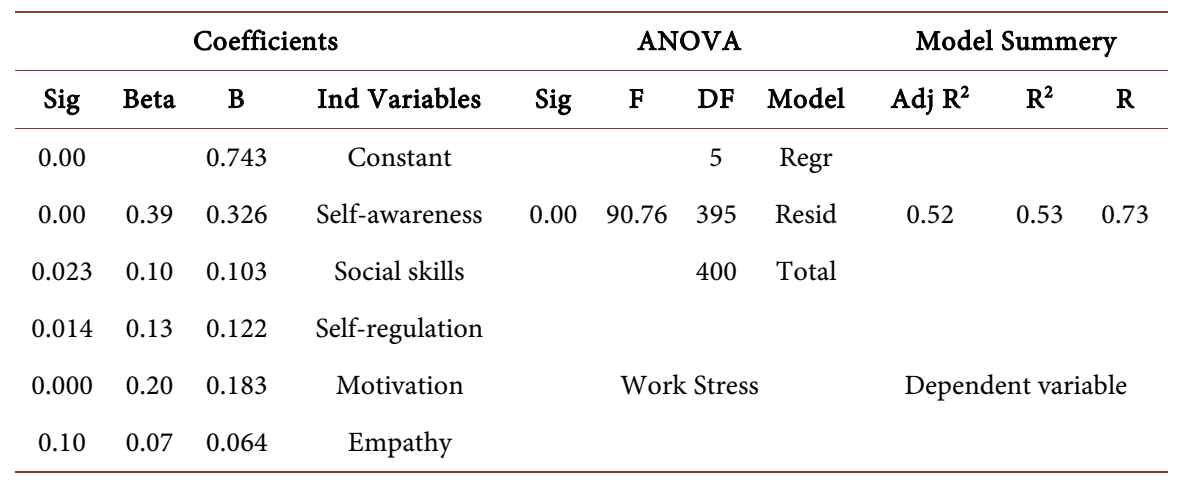


Table 3. Multiple regression: Effect of emotional intelligence on role conflict.

\begin{tabular}{ccccccccccc}
\hline & \multicolumn{3}{c}{ Coefficients } & & \multicolumn{3}{c}{ ANOVA } & \multicolumn{3}{c}{ Model Summery } \\
\hline Sig & Beta & B & Ind Variables & Sig & F & DF & Model & Adj R R $^{2}$ & $\mathbf{R}^{2}$ & R \\
\hline 0.01 & & 0.964 & Constant & & & 5 & Regr & & \\
0.40 & -0.04 & -0.04 & Self-awareness & 0.00 & 33.97 & 395 & Resid & 0.29 & 0.310 .548 \\
0.000 & 0.299 & 0.380 & Social skills & & & 400 & Total & & \\
0.000 & 0.241 & 0.279 & Self-regulation & & & & & & & \\
0.879 & -0.01 & -0.01 & Motivation & & Role Conflict & & & Dependent \\
0.01 & 0.142 & 0.152 & Empathy & & & & & & & \\
\hline
\end{tabular}

effect of emotional intelligence (self-awareness-social skills-self-regulationmotivation-empathy) on role conflict. As shown in Table 3.

From Table 3 it is clear that at the level of significance (0.05) there is a significant effect of a statistically significant effect of emotional intelligence on the role conflict, as the value of the level of statistical significance (Sig) in the analysis of variance ANOVA corresponding to the value $(\mathrm{F})$ The calculated one is less than 0.05 , and the coefficient of determination $\left(\mathrm{R}^{2}\right)$ is 0.31 , which means that emotional intelligence has explained $31 \%$ of the impact or change in the role conflict, while there are $69 \%$ due to other factors that the model did not address, as it turns out that three dimensions of Emotional intelligence (social skills-selfregulation-empathy) has a significant effect or statistical significance on the conflict of roles, as the level of statistical significance (Sig) of the regression coefficients is less than 0.05 , as the value of the level of statistical significance (Sig) of the regression coefficients is in order the dimensions of emotional intelligence (Self-awareness-social skills-self-regulation-motivation-empathy) are (0.40, $0.000,0.000,0.0879,0.01$ ) and they are all less than 0.05 except for the value of the level of morale for the two dimensions (motivation-self-awareness) greater than 0.05 .

It is also clear that the most influential dimension of emotional intelligence on the role conflict is (social skills), as it has the highest value of (Beta) coefficient of 0.38 , followed by (self-regulation) 0.27 , then (empathy) 0.15 .

\section{The second sub-hypothesis}

At the level of significance (0.05) there is a statistically significant effect of emotional intelligence (self-awareness-social skills-self-regulation-motivation-empathy) on the ambiguity of the role.

To test this hypothesis, multiple regression analysis was used to verify the effect of emotional intelligence (self-awareness-social skills-self-regulationmotivation-empathy) on role ambiguity. As shown in Table 4.

From Table 4 it is clear that at the level of significance (0.05) there is a significant effect of a statistically significant effect of emotional intelligence on the ambiguity of the role. Also, the coefficient of determination $\left(R^{2}\right)$ is 0.29 , which means that emotional intelligence explained $29 \%$ of the effect or change in the 
Table 4. Multiple regression the effect of emotional intelligence on role ambiguity.

\begin{tabular}{cccccccccccc}
\hline & \multicolumn{3}{c}{ Coefficients } & \multicolumn{4}{c}{ ANOVA } & \multicolumn{3}{c}{ Model Summery } \\
\hline Sig & Beta & B & Ind Variables & Sig & F & DF & Model & Adj $\mathbf{R}^{2}$ & $\mathbf{R}^{2}$ & $\mathbf{R}$ \\
\hline 0.012 & & 0.703 & Constant & & & 5 & Regr & & & \\
0.003 & 0.154 & 0.166 & Self-awareness & 0.00 & 32.95 & 395 & Resid & 0.28 & 0.29 & 0.543 \\
0.000 & 0.215 & 0.274 & Social skills & & & 400 & Total & & & \\
0.029 & 0.149 & 0.172 & Self-regulation & & & & & & & & \\
0.045 & 0.130 & 0.149 & Motivation & the ambiguity of the role & Dependent variable \\
0.577 & 0.032 & 0.034 & Empathy & & & & & & & & \\
\hline
\end{tabular}

ambiguity of the role, while there are $71 \%$ due to other factors that were not addressed by the model, as it turns out that all dimensions of emotional intelligence (self-awareness-Social skills-self-regulation-motivation) with the exception of (empathy) have a significant effect or statistical significance on the ambiguity of the role, as the level of statistical significance (Sig) for the regression coefficients is less than 0.05 , as the value of the level of statistical significance (Sig) for the regression coefficients is in order the dimensions of intelligence The emotional (self-awareness-social skills-self-regulation-motivationempathy) are $(0.003,0.000,0.029,0.045,0.577)$ and they are all less than 0.05 except for the value of the level of significance for the dimension (empathy) greater than 0.05 .

It is also clear that the most influential dimensions of emotional intelligence on role ambiguity are (social skills), as it has the highest value of (Beta) 0.27, followed by (self-awareness) 0.15 , then (self-regulation) 0.14 , then (motivation) 0.13 , and finally (empathy) 0.03 .

\section{The third sub-hypothesis}

At the level of significance (0.05) there is a statistically significant effect of emotional intelligence (self-awareness-social skills-self-regulation-motivation-empathy) on performance evaluation.

To test this hypothesis, multiple regression analysis was used to verify the effect of emotional intelligence (self-awareness-social skills-self-regulationmotivation-empathy) on performance evaluation. As shown in Table 5.

From Table 5 it is clear that at the level of significance (0.05) there is a significant effect of a statistically significant effect of emotional intelligence on the performance evaluation, as the value of the level of statistical significance (Sig) in the analysis of variance ANOVA corresponding to the value (F) Calculated is less than 0.05 , and the coefficient of determination $\left(R^{2}\right)$ is 0.41 , which means that emotional intelligence explained $41 \%$ of the impact or change in the performance evaluation, while there are $59 \%$ due to other factors that the model did not address, as it turns out that two dimensions of Emotional intelligence (self-awareness-motivation) has a significant effect or statistical significance on the performance evaluation, as the level of statistical significance (Sig) for the 
regression coefficients is less than 0.05 , as the value of the level of statistical sig-nificance ( $\mathrm{Sig}$ ) for the regression coefficients is in order the dimensions of emo-tional intelligence (self-awareness). Social skills-self-regulation-motivation-empathy) are $(0.000,0.589,0.648,0.000,0.339)$ and it is clear that the significance of the effect of each of (self-awareness-motivation) as the value of the level of morale for the two dimensions is less than 0.05 , while the effect of each is not significant From (Social Skills-Self-Organization-Coping) tuff), as the value of the level of significance for these dimensions is greater than 0.05 .

It is also clear that the most influential dimension of emotional intelligence on performance evaluation is (self-awareness), as it has the highest value of (Beta) coefficient of 0.53 , followed by (motivation) 0.22 and then (empathy) 0.05 .

\section{The Fourth sub-hypothesis}

At the level of significance (0.05), there is a statistically significant effect of emotional intelligence (self-awareness-social skills-self-regulation-motivation-empathy) on the physical work factors.

To test this hypothesis, multiple regression analysis was used to verify the effect of emotional intelligence (self-awareness-social skills-self-regulationmotivation-empathy) on physical work factors. As shown in Table 6.

From Table 6, it is clear that at the level of significance (0.05) there is a significant effect of a statistically significant effect of emotional intelligence on the performance evaluation, as the value of the level of statistical significance (Sig)

Table 5. Multiple regression effect of emotional intelligence on performance evaluation

\begin{tabular}{|c|c|c|c|c|c|c|c|c|c|c|}
\hline \multicolumn{4}{|c|}{ Coefficients } & \multicolumn{4}{|c|}{ ANOVA } & \multicolumn{3}{|c|}{ Model Summery } \\
\hline Sig & Beta & B & Ind Variables & Sig & $\mathrm{F}$ & DF & Model & Adj $R^{2}$ & $R^{2}$ & $\mathbf{R}$ \\
\hline 0.00 & & 0.949 & Constant & & & 5 & Regr & & & \\
\hline 0.000 & 0.518 & 0.532 & Self-awareness & 0.00 & 55.34 & 395 & Resid & 0.40 & 0.41 & 0642 \\
\hline 0.589 & -0.02 & -0.03 & Social skills & & & 400 & Total & & & \\
\hline 0.648 & -0.02 & -0.03 & Self-regulation & \multirow{3}{*}{\multicolumn{4}{|c|}{ Performance evaluation }} & \multirow{3}{*}{\multicolumn{3}{|c|}{$\begin{array}{c}\text { Dependent } \\
\text { variable }\end{array}$}} \\
\hline 0.000 & 0.208 & 0.226 & Motivation & & & & & & & \\
\hline 0.339 & 0.051 & 0.051 & Empathy & & & & & & & \\
\hline
\end{tabular}

Table 6. Multiple regression Effect of emotional intelligence on physical work factors.

\begin{tabular}{|c|c|c|c|c|c|c|c|c|c|c|}
\hline \multicolumn{4}{|c|}{ Coefficients } & \multicolumn{4}{|c|}{ ANOVA } & \multicolumn{3}{|c|}{ Model Summery } \\
\hline Sig & Beta & B & Ind Variables & Sig & F & $\mathrm{DF}$ & Model & $\operatorname{Adj} R^{2}$ & $\mathrm{R}^{2}$ & $\mathbf{R}$ \\
\hline 0.178 & & 0.312 & Constant & & & 5 & Regr & & & \\
\hline 0.000 & 0.536 & 0.589 & Self-awareness & 0.00 & 83.68 & 395 & Resid & 0.50 & 0.51 & 0717 \\
\hline 0.115 & -0.07 & -0.09 & Social skills & & & 400 & Total & & & \\
\hline 0.078 & 0.10 & 0.117 & Self-regulation & \multirow{3}{*}{\multicolumn{4}{|c|}{ Physical work factors }} & \multirow{3}{*}{\multicolumn{3}{|c|}{$\begin{array}{l}\text { Dependent } \\
\text { variable }\end{array}$}} \\
\hline 0.000 & 0.289 & 0.336 & Motivation & & & & & & & \\
\hline 0.361 & -0.04 & -0.04 & Empathy & & & & & & & \\
\hline
\end{tabular}


in the analysis of variance ANOVA corresponding to the value (F) Calculated is less than 0.05 , and the coefficient of determination $\left(\mathrm{R}^{2}\right)$ is 0.51 , which means that emotional intelligence has explained $51 \%$ of the impact or change that occurs to physical work factors, while there are $49 \%$ due to other factors that the model did not address, as it turns out that two of the dimensions of Emotional intelligence (self-awareness-motivation) has a significant effect or statistical significance on the physical factors of work, as the level of statistical significance (Sig) for the regression coefficients is less than 0.05 , as the value of the level of statistical significance ( $\mathrm{Sig}$ ) for the regression coefficients is in order the dimensions of emotional intelligence (awareness). In particular, social skills-self-regulation-motivation-empathy) are $(0.000,0.115,0.078,0.000,0.361)$ and it is clear that the significance of the effect of each of (self-awareness-motivation) as the value of the level of morale for the two dimensions is less than 0.05 , while the effect of the significance of the effect of (self-awareness-motivation) is less than 0.05. Each of social skills-organizing the Self-sympathy as the significance level of these dimensions is greater than 0.05 .

It is also clear that the most influential dimension of emotional intelligence on physical work factors is (self-awareness), as it has the highest value of (Beta) coefficient of 0.53 , followed by (motivation) 0.28 and then (self-regulation) 0.10 .

Accordingly, the first main hypothesis is accepted. There is a statistically significant effect of emotional intelligence (self-awareness-social skills-self-regulation-motivation-empathy) on work stress.

\subsection{Second Main Hypothesis}

At the level of significance (0.05) there is a statistically significant effect of emotional intelligence with the presence of the Gender as a moderating variable (moderator) on work stress.

To test this hypothesis and its sub-hypotheses, hierarchical multiple regression analysis was used to measure the effect of emotional intelligence on work stress in the presence of a moderating variable (Gender) as shown in Table 7.

Table 7. Results of the first model and second model.

\begin{tabular}{|c|c|c|c|c|c|c|c|}
\hline \multirow{2}{*}{$\begin{array}{c}\text { Dependent } \\
\text { Variable }\end{array}$} & \multicolumn{3}{|c|}{ Second Model } & \multicolumn{3}{|c|}{ First Model } & \multirow{2}{*}{ Independent Variables } \\
\hline & Sig & $\mathrm{T}$ & B & Sig & $\mathrm{T}$ & B & \\
\hline \multirow{7}{*}{ Work Stress } & & - & & 0.000 & 20.364 & 0.809 & Emotional intelligence \\
\hline & 0.000 & 20.168 & 0.802 & & - & & $\begin{array}{c}\text { Emotional } \\
\text { intelligence } \times \text { Gender }\end{array}$ \\
\hline & & 0.717 & & & 0.714 & & $\mathrm{R}$ \\
\hline & & 0.515 & & & 0.510 & & $\mathrm{R}^{2}$ \\
\hline & & 0.005 & & & 0.510 & & $\mathrm{R}^{2} \Delta$ \\
\hline & & 3.977 & & & 414.707 & & $\mathrm{~F}$ \\
\hline & & 0.047 & & & 0.000 & & $\mathrm{~F} \Delta \mathrm{Sig}$ \\
\hline
\end{tabular}


Table 7 displays the results of the first model, which show that the value of the correlation coefficient $(\mathrm{R}=0.714$, and the value of the coefficient of determination $\left(\mathrm{R}^{2}=0.510\right)$, and this means $51 \%$ of the changes in work stress are caused by the change in emotional intelligence (emotional intelligence explained $51 \%$ of the changes). The incident in work stress and the rest of the percentage is due to other factors that were not covered by the study model), and the results showed a statistically significant effect of the emotional intelligence variable on work stress, where the value of $\mathrm{F}=417.7$ with a level of significance (Sig = $0.000)$, which is less than 0.05 , and it reached The value of the impact score is $(\beta)$ $=0.809$ This means that a one-degree increase in the level of emotional intelligence leads to an increase in work stress of 0.809 .

In the second model, the moderating variable (Gender) was entered into the regression model, where the value of the correlation coefficient increased to be-come $(\mathrm{R}=0.717)$, as well as the value of the coefficient of determination $2 \mathrm{R}$, where it increased to become $(0.515)$, i.e. by $(0.005)$, and this ratio is statistically significant, as it was The change in the value of (F 3.977) $\Delta \mathrm{F}=$ and at the level of significance (Sig =0.047.), which is less than (0.05), and the effect degree value was $0.802(\beta)$ in the presence of the adjusted variable (Gender) and the calculated $t$ value was $(t=20.16)$ with a level of significance ( $\operatorname{tig}=0.000)$, and this confirms the role The moral of the moderating variable (Gender) in improving the impact of emotional intelligence on work stress, as the percentage of interpretation of the variance in work stress improved by $0.05 \%$-albeit slight-(to rise from $51 \%$ to $51.5 \%$. Accordingly, there is a significant statistically significant effect from Emotional intelligence with gender as a moderator on work stress.

\subsection{The Third Main Hypothesis}

At the level of significance (0.05) there is a statistically significant effect of emotional intelligence with the presence of experience as a moderating variable (moderator) on work stress.

To test this hypothesis and its sub-hypotheses, hierarchical multiple regression analysis was used to measure the effect of emotional intelligence on work stress in the presence of experience as a moderator as shown in Table 8.

Table 8. Results of the third model.

\begin{tabular}{|c|c|c|c|c|c|c|c|}
\hline \multirow{2}{*}{$\begin{array}{c}\text { Dependent } \\
\text { Variable }\end{array}$} & \multicolumn{3}{|c|}{ Third Model } & \multicolumn{3}{|c|}{ First Model } & \multirow{2}{*}{ Independent Variables } \\
\hline & Sig & $\mathrm{T}$ & B & Sig & $\mathrm{T}$ & B & \\
\hline \multirow{7}{*}{ Work Stress } & & - & & 0.000 & 20.364 & 0.809 & Emotional intelligence \\
\hline & 0.000 & 20.168 & 0.807 & & - & & Emotional intelligence $\times$ Experience \\
\hline & & 0.714 & & & 0.714 & & $\mathrm{R}$ \\
\hline & & 0.510 & & & 0.510 & & $\mathrm{R}^{2}$ \\
\hline & & 0 & & & 0.510 & & $\mathrm{R}^{2} \Delta$ \\
\hline & & 0.048 & & & 414.707 & & $\mathrm{~F}$ \\
\hline & & 0.826 & & & 0.000 & & $\mathrm{~F} \Delta \mathrm{Sig}$ \\
\hline
\end{tabular}


The third model shows, the moderating variable (experience) was entered into the regression model, where the value of the correlation coefficient did not change, and it was the same $(R=0.714)$, as well as the value of the coefficient of determination $2 \mathrm{R}$ did not change, and it was the same as $\mathrm{R}^{2}=0.0510$, and this ratio is not statistically significant, Where the change in the value of $(\mathrm{F}=0.048)$ $\Delta \mathrm{F}$ was at a level of significance.

$(\operatorname{Sig}=0.826)$, which is greater than $(0.05)$, and the effect degree value was $0.807(\beta)$ in the presence of the adjusted variable (experience) and the calculated $t$ value was $(t=20.16)$ with a level of significance ( $\operatorname{Sig}=0.000)$, and this confirms that there is no A significant role of the moderating variable (experience) in improving the impact of emotional intelligence on work stress, as the percentage of interpretation of the variation in work stress did not improve and remained the same $51 \%$. Accordingly, there is no significant statistically significant effect of emotional intelligence in the presence of experience as a moderating variable on work pressures.

\subsection{The Fourth Main Hypothesis}

At the level of significance (0.05) there is a statistically significant effect of emotional intelligence with the presence of the educational level as a moderating variable (moderator) on work stress.

To test this hypothesis and its sub-hypotheses, hierarchical multiple regression analysis was used to measure the effect of emotional intelligence on work stress in the presence of a moderating variable educational level as shown in $\mathrm{Ta}$ ble 9.

In the fourth model, the moderating variable (the educational level) was entered into the regression model, where the value of the correlation coefficient increased to become $(\mathrm{R}=0.767)$, as well as the value of the coefficient of determination $2 \mathrm{R}$, where it increased to become $(0.588)$, i.e. by $(0.078)$, and this ratio is statistically significant, as The change in the value of (F75.73) was $\Delta \mathrm{F}$, with a significance level $(\mathrm{Sig}=0.000)$, which is less than $(0.05)$, and the effect degree

Table 9. Results of the fourth model.

\begin{tabular}{|c|c|c|c|c|c|c|c|}
\hline \multirow{2}{*}{$\begin{array}{l}\text { Dependent } \\
\text { Variables }\end{array}$} & \multicolumn{3}{|c|}{ Fourth Model } & \multicolumn{3}{|c|}{ First Model } & \multirow{2}{*}{ Independent Variables } \\
\hline & Sig & $\mathrm{T}$ & B & Sig & $\mathrm{T}$ & B & \\
\hline \multirow{7}{*}{ Work Stress } & & - & & 0.000 & 20.364 & 0.809 & Emotional intelligence \\
\hline & 0.000 & 19.11 & 0.722 & & - & & $\begin{array}{c}\text { Emotional intelligence } \\
\times \text { Educational level }\end{array}$ \\
\hline & & 0.767 & & & 0.714 & & $\mathrm{R}$ \\
\hline & & 0.588 & & & 0.510 & & $\mathrm{R}^{2}$ \\
\hline & & 0.078 & & & 0.510 & & $\mathrm{R}^{2} \Delta$ \\
\hline & & 75.73 & & & 414.707 & & $\mathrm{~F}$ \\
\hline & & 0.000 & & & 0.000 & & $\mathrm{~F} \Delta \mathrm{Sig}$ \\
\hline
\end{tabular}


value was $0.722(\beta)$ in the presence of the adjusted variable (Gender) and the calculated $t$ value was $(t=19.11)$ with a level of significance ( $\mathrm{Sig}=0.000)$, and this confirms the moral role For the moderating variable (school level) in improving the impact of emotional intelligence on work stress, the percentage of explanation for the variation in work stress improved by $0.078 \%$ (to rise from $51 \%$ to $58.8 \%$. Accordingly, there is a significant statistically significant effect of emotional intelligence with the presence of the educational level A modifier on work stress.

\subsection{Fifth Main Hypothesis}

At the level of significance (0.05) there is a statistically significant effect of emotional intelligence with the presence of a moderating variable managerial level on work stress.

To test this hypothesis and its sub-hypotheses, hierarchical multiple regression analysis was used to measure the impact of emotional intelligence on work stress in the presence of a moderating managerial level as shown in Table 10.

In the fifth model, the moderating variable (managerial level) was entered into the regression model, where the value of the correlation coefficient increased to become $(R=0.742)$, as well as the value of the coefficient of determination $2 \mathrm{R}$, where it increased to become $(0.551)$, i.e. by $(0.041)$, and this ratio is statistically significant, as The change in the value of (F 75.73) was $\Delta \mathrm{F}$, with a significance level $(\mathrm{Sig}=0.000)$, which is less than $(0.05)$, and the effect degree value was $0.740(\beta)$ in the presence of the adjusted variable (Gender) and the calculated $t$ value was $(\mathrm{t}=18.65)$ with a level of significance ( $\mathrm{Sig}=$ 0.000 ), and this confirms the moral role For the moderating variable (managerial level) in improving the impact of emotional intelligence on work stress, as the percentage of interpretation of the variance in work stress improved by $0.041 \%$ (to rise from $51 \%$ to $55.10 \%$. Accordingly, there is a significant statistically significant effect of emotional intelligence in the presence of the managerial level A moderator on work stress.

Table 10. Results of the fifth model.

\begin{tabular}{|c|c|c|c|c|c|c|c|}
\hline \multirow{2}{*}{$\begin{array}{c}\text { Dependent } \\
\text { Variable }\end{array}$} & \multicolumn{3}{|c|}{ Fifth Model } & \multicolumn{3}{|c|}{ First Model } & \multirow{2}{*}{ Independent Variables } \\
\hline & Sig & $\mathrm{T}$ & B & Sig & $\mathrm{T}$ & B & \\
\hline \multirow{7}{*}{ Work Stress } & \multirow{3}{*}{0.000} & - & \multirow{3}{*}{0.740} & 0.000 & 20.364 & \multirow[t]{7}{*}{0.809} & Emotional intelligence \\
\hline & & 18.65 & & & - & & $\begin{array}{c}\text { Emotional intelligence } \\
\times \text { Managerial level }\end{array}$ \\
\hline & & 0.742 & & & 0.714 & & $\mathrm{R}$ \\
\hline & & 0.551 & & & 0.510 & & $\mathrm{R}^{2}$ \\
\hline & & 0.041 & & & 0.510 & & $\mathrm{R}^{2} \Delta$ \\
\hline & & 36.69 & & & 414.707 & & $\mathrm{~F}$ \\
\hline & & 0.000 & & & 0.000 & & $\mathrm{~F} \Delta \mathrm{Sig}$ \\
\hline
\end{tabular}




\section{Results}

- There is a significant effect of statistically significant effect of emotional intelligence on work stress

- There is a statistically significant effect of emotional intelligence (self-awareness-social skills-self-regulation-motivation-empathy) on the role conflict, ambiguity of the role, performance evaluation and the performance evaluation.

- There is a statistical difference in emotional intelligence on conflict ambiguity due to gender

- There is no statistical difference in emotional intelligence on conflict ambiguity due to experience.

- There is a statistical difference in emotional intelligence on conflict ambiguity due to educational level.

- There is a statistical difference in emotional intelligence on conflict ambiguity due to: managerial levels.

\section{Recommendations}

- Organizations should pay more attention to Emotional Intelligence and its practices and should give it a priority in managerial work and the necessity to develop the managers' capabilities and skills, especially those who are involved in strategic decisions.

- Developing the workers' skills in order to handle the different methods of artificial and emotional intelligence, and working on identifying the scientific and objective basis that should be adopted in decision-making.

- Paying more attention to emotional intelligence dimensions, developing and designing training programs for staff to raise their knowledge and skills level in terms of emotional intelligence and organizational citizenship behaviors.

- Organizations should have benefited from the high level of emotional intelligence of employees and develop their skills. Additionally to decrease the workload.

- Emotional intelligence must be a part of employees training to uphold employees' ability to develop a successful performance with their organization. To intensify training programs on how to deal with the work stressors.

- Organizations should reduce work stress by reducing conflicts in a working relationship, career development, and working environment in order to improve employee job performance.

\section{Conclusions}

The fundamental thought underlying the notion of emotional intelligence is that efficacious actions entail more than pristinely rational thought. Emotion is segregating for bracing and arranging behavior.

The research was able to establish that there is a significant relationship between employees' emotional intelligence and work stress. The results of this 
study showed a relationship between emotional intelligence and reducing work stress for all three management levels.

There are some limitations that make a little bit deficiency of this study. Firstly, the current study relied on data collected through questionnaires and surveys, and some of the scales used may be erroneous or inaccurate. There may also have been recalling issues, because the respondents may not have been able to accurately report previous experiences. The other limitation that should be addressed by future research is to use alternative data collection techniques, such as semi-structured interviews or focus groups.

Finally, it is very important that the working environment is being continuously monitored for stress-related factors. Further, it is not only important to monitor the factors but to create a healthy environment in which employees work in an efficient way and there should be a proper reward system which would motivate the employees to do work in an efficient way.

\section{Conflicts of Interest}

The authors declare no conflicts of interest.

\section{References}

[1] Chhabra, B. and Mohanty, R. (2013) Effect of Emotional Intelligence on Work Stress-A Study of Indian Managers. International Journal of Indian Culture and Business Management, 6, 300-313. https://doi.org/10.1504/IJICBM.2013.053104

[2] Rashid, A., Bajwa, R. and Batool, I. (2016) Effect of Emotional Intelligence on Job Stress, Job Satisfaction and Organizational Commitment among Bank Employees. Pakistan Journal of Social Sciences, 36, 141-149.

[3] Henry, O. and Evans, A.J. (2008) Occupational Stress in Organizations. Journal of Management Research, 8, 123-135.

[4] Ismail, A., Yao, A., Yeo, E., Lai-Kuan, K. and Soon-Yew, J. (2010) Occupational Stress Features, Emotional Intelligence and Job Satisfaction: An Empirical Study in Private Institutions of Higher Learning. Revista Científica Electrónica Ciencias Gerenciales, 16, 5-33. https://www.revistanegotium.org.ve

[5] Gunu, U. and Oladepo, R.O. (2014) Impact of Emotional Intelligence on Employees' Performance and Organizational Commitment: A Case Study of Dangote Flour Mills Workers.

[6] Shehu, L. and Kida, M. (2019) The Effect of Emotional Intelligence on Employees Performance. Review of Public Administration and Management, 6, 22-32.

[7] Ekienabor, E. (2019) Impact of Job Stress on Employees' Productivity and Commitment. International Journal for Research in Business, Management, and Accounting, 2, 124-133.

[8] Vijayan, M. (2018) Impact of Job Stress on Employees' Job Performance in Aavin, Coimbatore. Journal of Organisation \& Human Behaviour, 6, 21-29.

[9] Pandey, D. (2020) Work Stress and Employee Performance: An Assessment of Impact of Work Stress. International Research Journal of Human Resource and Social Sciences, 7, 124-135.

[10] Rasheed, M.I. and Nisar, S.K. (2019) Stress and Performance: Investigating Relationship between Occupational Stress, Career Satisfaction, and Job Performance of 
Police Employees. Journal of Public Affairs, 20, e1986.

[11] Khuong, M.N. and Yen, V.H. (2016) Investigate the Effects of Job Stress on Employee Job Performance-A Case Study at Dong Xuyen Industrial Zone, Vietnam. International Journal of Trade, Economics and Finance, 7, 31-37. https://doi.org/10.18178/ijtef.2016.7.2.495

[12] Madi, K.M.S. (2014) The Relationship between Manager's Emotional Intelligence and Organizational Conflict Management: An Applied Study in Local Government Organizations in Kafr El-Sheikh Governorate. Menoufia University, Faculty of Commerce, Al-Menoufia.

[13] Elshawa, J.M.M. (2015) Emotional Intelligence and Its Relationship with Organizational Citizenship Behaviors: An Empirical Study on the Bank of Palestine in Gaza Governorates, Al-Azhar University Gaza.

[14] Banat, A.-K.S. (2009) Work Stress and Its Impact on the Performance of the Palestinian Telecommunications Company Employees in Gaza Strip District, Islamic University Gaza.

[15] Hair, J.F., Risher, J.J., Sarstedt, M. and Ringle, C.M. (2019) When to Use and How to Report the Results of PLS-SEM. European Business Review, 31, 2-24.

https://doi.org/10.1108/EBR-11-2018-0203 